\title{
Determination of Liquefied Petroleum Flame Temperatures using Emission Spectroscopy
}

\author{
Dermeval Carinhana Jr., ${ }^{*}, a$ Luiz G. Barreta, ${ }^{a}$ Cláudio J. Rocha, ${ }^{a}$ Alberto M. dos Santos ${ }^{a}$ \\ and Celso A. Bertran ${ }^{b}$
}

${ }^{a}$ Instituto de Estudos Avançados, CP 6044, 12228-970, São José dos Campos-SP, Brazil

${ }^{b}$ Instituto de Química, Universidade Estadual de Campinas, CP 6154, 13084-862 Campinas-SP, Brazil

\begin{abstract}
A espectroscopia de emissão foi utilizada na determinação da temperatura de chamas prémisturadas de GLP. Investigou-se a emissão natural de radicais $\mathrm{CH}^{*}$ em três diferentes condições de queima: razão estequiométrica de combustível/oxidante, excesso de combustível (chama rica) e excesso de oxidante (chama pobre). O valor médio obtido para a temperatura rotacional de $\mathrm{CH}^{*}$ foi de $2845 \pm 70 \mathrm{~K}$ nas condições utilizadas nos experimentos. Esse valor não variou significativamente com os demais tipos de chama e é compatível com os cálculos de temperatura adiabática dos sistemas estudados. Essa temperatura também é concordante com resultados obtidos por via indireta, utilizando-se o método de linha reversa de sódio, que consiste em uma técnica bem estabelecida e independente da emissão natural. Temperaturas vibracionais de ca. $4600 \mathrm{~K}$ foram calculadas, indicando que o tempo de vida do $\mathrm{CH}^{*}$ não é suficiente para que o equilíbrio entre os modos rotacionais e vibracionais seja estabelecido.
\end{abstract}

Emission spectroscopy was used in the temperature determination of LPG (liquefied petroleum gas) premixed flames. Natural emission of $\mathrm{CH}^{*}$ radicals was investigated in flames under three different burning conditions: fuel/oxydizer stoichiometric ratio, fuel excess (rich flame), and oxidizer excess (lean flame). An average value of $2845 \pm 70 \mathrm{~K}$ was obtained for $\mathrm{CH}^{*}$ rotational temperature in the set up used in the experiments. This value did not show significant change with the type of flame analyzed and it is compatible with the calculated adiabatic flame temperatures of the investigated systems. This temperature value also agrees with that determined by an indirect measurement, using the sodium line reversal method, which is independent from the radical natural emission and well established in literature. Vibrational temperatures of ca. $4600 \mathrm{~K}$ were calculated, indicating that the $\mathrm{CH}^{*}$ lifetime is insufficient for the establishment of an equilibrium state between the rotational and vibrational modes.

Keywords: chemiluminescence, premixed flames, Boltzmann distribution, combustion diagnostics

\section{Introduction}

In an adiabatic flame all released heat by exothermic chemical reactions, at constant pressure, is absorbed by the combustion products, without heat transfer to the surroundings. ${ }^{1}$ This temperature corresponds to the highest temperature that can be achieved by a flame. However, the lack of thermal equilibrium in a real flame does not permit the use of the classical temperature concept, as a kinetic energy measurement, in these systems. Nevertheless, in this case we may consider the concepts of rotational temperature, vibrational temperature and electronic

*e-mail: derms@ieav.cta.br temperature..$^{2-6}$ In flames, rotational temperature is very close to the kinetic temperature, due to the quick transfer between translational and rotational energies. ${ }^{7}$ In this way, rotational temperature measurement is as a good indicative of flame temperature.

Flame temperature determination provides important information about released heat resulting from chemical reactions in combustion systems. ${ }^{8}$ Temperature distribution knowledge in a combustion chamber may indicate eventual project problems and the necessity of construction optimization of these devices. ${ }^{9}$ Temperature diagnosis, usually, is carried out by thermocouples and suction pyrometers. Both techniques are intrusive, because these devices are inserted in the flames, changing its intrinsic 
characteristics. The values obtained correspond to an average measurement, especially in the case of small flames. ${ }^{8}$ In thermocouple applications, a large radical concentration in flames may induce catalytic processes on its surface, resulting in significant errors in temperature determination. ${ }^{9}$

Contrary to the aforementioned latter methods, radiation emission and absorption, on the other hand, by hot gas flames have an absolutely non-intrusive characteristic. Both, especially emission, offer the possibility of temperature monitoring and excited state studies from the ultraviolet to infrared spectra. ${ }^{10,11}$ Most of the optical methods are based on lasers, as laser absorption spectroscopy, laser induced fluorescence (LIF), Raman spectroscopy and coherent anti-Stokes Raman spectroscopy (CARS) ${ }^{12}$ However, these techniques can not be applied in some situations, due its complex experimental apparatus. ${ }^{13}$ In fact, the real time monitoring of temperature of some airborne combustion systems, such as aircraft turbines or rocket engines, is very complicated, or impossible, when employing laser devices which require less drastic working conditions. Mechanical vibrations, for example, can easily damage the system alignment. In this case, natural emission of species presents in flames has been used. ${ }^{14-16}$ Besides non-intrusive characteristic and simpler requirements, emission spectroscopy is also favored by the nature of the probe species. First, flame emission is strongly associated to the diatomic molecules. Spectroscopy constants for these species are very well determined, which required lower calculations for temperature determination. Second, natural emission occurs near the region where they were generated, due to their small emission life time. ${ }^{17}$ This can be used to relate the information obtained from flame emission spectra to the temperature or concentrations at a specific flame region. ${ }^{5}$

Spontaneous or natural emission in flames is due to chemical reactions that produce chemical species in excited state. This phenomenon is also known as chemiluminescence. The most intense emissions are due to $\mathrm{C}_{2}{ }^{*}, \mathrm{CH}^{*}$ e $\mathrm{OH}^{*}$ species. ${ }^{18,19} \mathrm{OH}^{*}$ has been the most used radical in flame temperature determination, since this species can be found in substantial concentrations in the hot zones of most flames. ${ }^{9}$ However, measured temperatures in an atmospheric methane flames using natural emission technique showed values hundreds of degrees higher than flame adiabatic temperature. ${ }^{20,21}$ This abnormal behavior was associated to the a non-equilibrium state of $\mathrm{OH}^{*}$ in the flame inner cone.

Radical $\mathrm{CH}^{*}$ has been used in flame mapping, due to its also intense emission bands in the ultraviolet-visible spectrum, ${ }^{22}$ which is concentrated mainly in the flame inner cone. $\mathrm{CH}^{*}$ radical most intense emission band system is observed around $431.5 \mathrm{~nm}$, which corresponds to the $\left(\mathrm{A}^{2} \Delta-\mathrm{X}^{2} \Pi\right)$ transition. ${ }^{23}$ The $\mathrm{Q}$ branch of $0-0$ vibrational band originates a strong peak at $431.25 \mathrm{~nm}$. In this spectrum region, there is also the presence of 1-1 vibrational band, less intense. At $432.4 \mathrm{~nm}$ an intense peak is observed attributed to the 2-2 vibrational band.

$\mathrm{CH}^{*}$ natural emission was used to determine temperatures in the past. Most studies have focused on low pressure plasmas and flames, ${ }^{14,15,24,25}$ which allow better conditions to understand the combustion processes investigated. In this situation, lower collision ratio, if compared to atmospheric flames, produces a more specific radical deactivation process, which returns a less complex emission spectrum. This allows faster and simpler calculations of rotational or vibrational temperatures and, additionally, of some spectroscopy parameters, such as rotational and vibrational energy transfer ratios. ${ }^{26}$ However, in low pressure conditions, the frequency of collisions for diatomic radicals is sufficient to establish the equilibrium of the rotational states, i.e., a Boltzmann's distribution, but may not be enough for thermal equilibrium. Thus, in these cases, we cannot take rotational temperature as flame temperature. Atmospheric systems also were studied by natural emission, but to a lower extent. Additionally, results are inconclusive: measurements in atmospheric acetylene flames returned an over-adiabatic rotational temperature, ${ }^{18}$ while other studies with atmospheric plasmas showed that $\mathrm{CH}^{*}$ rotational temperature can be assigned to the gas temperature. ${ }^{27}$

The aim of the present work is to establish a reliable non-intrusive method of temperature determination of the atmospheric combustion system by emission spectroscopy. The development of this method is part of a Brazilian effort to project and construct hypersonic vehicles, commonly named "scramjets". In these vehicles, combustion takes place at supersonic speeds, generated by hypersonic shock waves, which eliminate the employment of intrusive temperature sensors, such as thermocouples. In this work, Liquefied Petroleum Gas was used as fuel due to its low cost and because at the moment only small organic molecules, mainly methane and acetylene, were studied using optical combustion diagnostic techniques.

\section{Temperature calculation}

The rotational temperature can be determined from the ro-vibrational emission spectra of the chemical species in the flames. This technique is known as Boltzmann plot method and is based on the measurement of the relative peak intensities of emission spectrum species. The relation 
between the peak intensity (I) and the temperature (T) is given by $(1):{ }^{15,28}$

$$
I=C S_{J^{\prime} J^{\prime \prime}} \lambda^{-4} \exp \left(\frac{-E_{J^{\prime}}}{k T}\right)
$$

where $\mathrm{S}_{J^{\prime} J^{\prime}}$ is the line strength of a transition from the upper $\left(J^{\prime}\right)$ and lower $\left(J^{\prime}\right)$ rotational state; $\mathrm{E}_{J^{\prime}}$ is energy of the upper level and $\mathrm{C}$ a proportionality constant. In a good approximation, if we consider a group of emission lines of the same ro-vibronic band, the vibrational and electronic part of the line strength are equal for all transitions in the band. So, if the system presents a Boltzmann distribution, a plot of natural logarithm of line intensities versus energy level returns a straight line, whose slope is the inverse of rotational temperature.

As mentioned in Introduction, temperature calculation in atmospheric flames by using natural emission technique has shown some results that are not reliable. Thus, in this study we employed another technique to validate natural emission temperature results. The chosen technique was line reversal method. ${ }^{29,30}$ This method is based on the measurement of electronic temperature of ions inserted in flames. The most common is the $\mathrm{Na}^{+}$species. Although it is an intrusive process, this is a simple and well established method, which has been largely used in the last decades. This method is based on Kirchhoff's law, which states that for a gas in thermodynamic equilibrium the emissivity $(\alpha)$ is equal to the absorption coefficient $(\varepsilon)$ values. Temperature is determined by comparison between the emission intensity of a seeded species in the flame, usually sodium atoms, and the radiation from a black body, simulated by a heated lamp filament, transmitted through the flame hot gases. In this situation, the total radiation flux $(\Phi)$ which reaches the light detector is given by:

$\Phi=\Phi_{\mathrm{f}}+(1-\varepsilon) \Phi_{\text {lamp }}$

where $\Phi_{\mathrm{fl}}$ is the radiation flux emitted by the flame, (1- $\varepsilon$ ) is the flame transmittance and $\Phi_{\text {lamp }}$ is the flux emitted by the filament lamp. All $\Phi$ values depend on the solid angle $(\Omega)$ of the employed optics, the radiation wavelength $(\lambda)$ and the emitters temperature $(\mathrm{T})$.

In an experimental apparatus where $\Omega$ is kept constant and the used spectral range is sufficiently narrow, $\Phi$ is an exclusive function of T. If the validity of Kirchhoff's law is assumed, i.e., $\varepsilon=\alpha$, the system shows no difference between absorbed and emitted radiation by the flame. This condition makes the comparison between $\Phi_{\mathrm{fl}}$ and $\Phi_{\text {lamp }}$ possible. Consequently, the relation between $\Phi$ and $\mathrm{T}$ is: a) $\Phi_{\mathrm{f}}>\Phi_{\text {lamp }} \Rightarrow \mathrm{T}_{\mathrm{f}}>\mathrm{T}_{\text {lamp }}$

b) $\Phi_{\mathrm{f}}=\Phi_{\text {lamp }} \Rightarrow \mathrm{T}_{\mathrm{f}}=\mathrm{T}_{\text {lamp }}$

c) $\Phi_{\mathrm{f}}<\Phi_{\text {lamp }} \Rightarrow \mathrm{T}_{\mathrm{f}}<\mathrm{T}_{\text {lamp }}$

where $\mathrm{T}_{\mathrm{ff}}$ and $\mathrm{T}_{\text {lamp }}$ are the flame and the lamp temperatures respectively. Equation 3b, shows the so-called inversion point, i.e., where both flame and lamp spectra show the same intensity and, as consequence, the same temperature. If the lamp temperature is calibrated against another temperature standard, such as optical pyrometers, flame temperature can be determined.

Despite the relative instrumental simplicity and reliability of the line reversal technique, there are some conditions which may affect the temperature results, such as solid particles in flames or the presence of a cool boundary layer. ${ }^{29}$ Solid particles, like soot, seed, ash or unburned fuel, act as black body emitters and absorbers, and also scattered radiation out of the lamp incident beam. This superimposed effect makes the determination of the real reversal point difficult. The presence of a cool boundary layer produced by a broadening of atomic emission line causes a re-absorption of the radiation emitted by the center of the line, which diminishes the temperature obtained. However, effects can be neglected in several cases. Flames with equivalent ratio fuel/oxidant near 1.0 (stoichiometric condition) do not present unburned fuel and do not produce soot or ash. In the same way, small open flames, like atmospheric flames, do not show remarkable differences of temperature between bulk and boundary layer regions. Thus, this technique can be used to validate natural emission results without any corrections.

\section{Experimental}

Ro-vibrational emission spectra of $\mathrm{CH}^{*}$ radicals were used to determine the temperature of liquefied petroleum gas (LPG) flames, for three different equivalence ratios: $\phi=0.78$ (lean flame), $\phi=1.02$ (stoichiometric flame) and $\phi=1.43$ (rich flame). A premixed type home-built burner based on a previous published work was used in the experiments. ${ }^{31}$ State-steady flames were produced from a gaseous mixture of LPG/atmospheric air/oxygen. The extra oxygen was used to achieve the desired equivalence ratio. Several gas flows were tested and the three combinations which produced more stable flames were selected. These correspond to the effective work range of the burner used, i.e., for lower or higher gas flows it is impossible to create a stable flame. LPG is an equimolar propane/n-butane mixture. The burner supply was controlled by calibrated flow meters. Molar flows of the gaseous mixture are listed in Table 1. 
Table 1. Burner conditions used in chemiluminescence measurements

\begin{tabular}{lccc}
\hline Flame / $(\phi)$ & $\begin{array}{c}\text { Total } \mathrm{O}_{2} / \\
\left(\mathrm{mmol} \mathrm{min}^{-1}\right)\end{array}$ & $\begin{array}{c}\mathrm{N}_{2} / \\
\left(\mathrm{mmol} \mathrm{min}^{-1}\right)\end{array}$ & $\begin{array}{c}\mathrm{LPG} / \\
\left(\mathrm{mmol} \mathrm{min}^{-1}\right)\end{array}$ \\
\hline Rich (1.43) & 21.2 & 27.9 & 6.3 \\
Stoichiometric (1.02) & 35.5 & 27.9 & 6.3 \\
Lean (0.78) & 46.8 & 27.9 & 6.3 \\
\hline
\end{tabular}

The optical system used consisted of a TRIAX 550 (Jobin Yvon) monochromator of $0.5 \mathrm{~m}$ focal length (f), equipped with a 1200 lines $\mathrm{mm}^{-1}$ diffraction grating, with blaze at $500 \mathrm{~nm}$. The slit width was fixed at $10 \mu \mathrm{m}$. Emission signal was detected by a Hamamatsu R928P phototube, with $950 \mathrm{~V}$ as work voltage. Spectra were obtained at 415 to $440 \mathrm{~nm}$ range, which correspond to $\mathrm{A}^{2} \Delta \rightarrow \mathrm{X}^{3} \Pi$ electronic band of the $\mathrm{CH}^{*}$ radical. With these experimental conditions, the spectral resolution obtained was ca. $0.04 \mathrm{~nm}$. This value was determined by a calibration with a $\mathrm{Hg}$ discharge lamp.

The burner was mounted on a translation stage with mobility in the three orthogonal directions ( $\mathrm{x}, \mathrm{y}$ and $\mathrm{z}$ ). This set up allowed spectra recording at different distances above burner along the principal flame axis, at regular intervals of $1 \mathrm{~mm}$, starting at the initial value of $2.5 \mathrm{~mm}$ (with reference to the outlet of the burner) and ending at the maximum value of $22.5 \mathrm{~mm}$.

A quartz lens, with $\mathrm{f}=100 \mathrm{~mm}$ and diameter of 2 " was used for light collection. The flame image was projected on the spectrometer entrance slit in a 1:1 ratio. All intensities were corrected by optical response curves of the employed gratings and phototube given by the manufacturers. The apparatus scheme is shown in Figure 1.

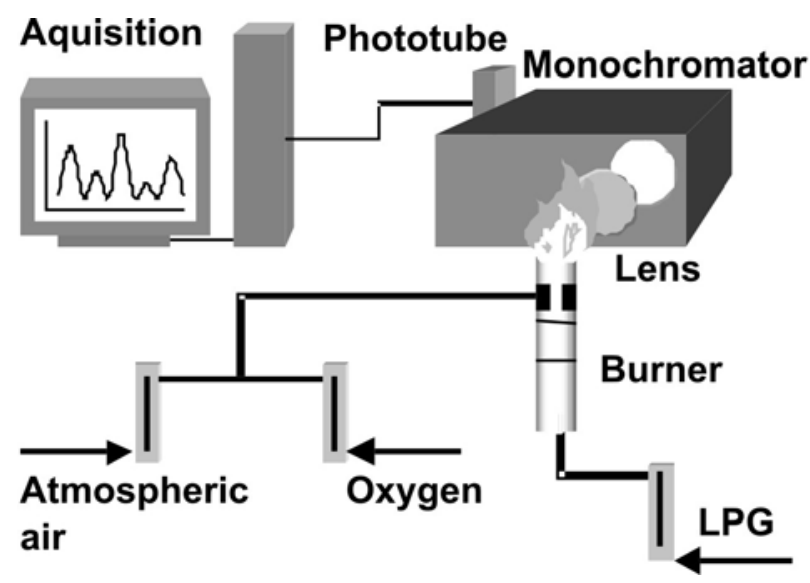

Figure 1. Experimental apparatus utilized in spectra records.

Rotational temperature was determined by comparison between experimental and simulated spectra. These were calculated using a free code, named LIFBASE. ${ }^{32}$ This software has an internal data bank containing all useful molecular spectroscopy data for many diatomic species important in combustion, including the $\mathrm{CH}^{*}$ radical. With LIFBASE, spectra were simulated at different temperatures and compared, in an interactive graphic interface, with experimental data. Temperature values were assigned according to the better agreement between both spectra, using as reference the statistical parameter variance, i.e., the sum of the square of the intensity deviations. The overall experimental spectral resolution was also required. This parameter is generally defined as the full-width at the halfheight peak. Flame adiabatic temperatures were calculated by the free software GASEQ. ${ }^{33}$

Radical temperature was also determined using the Boltzmann plot method, described in Introduction. We used the full peak intensity at the half-width for rotational temperature calculations. Spectroscopic data employed in this method were obtained in literature works. ${ }^{15,34}$ For the sodium line reversal experiments, $\mathrm{Na}$ was seeded in the flame, inserted as $\mathrm{NaCl}$ crystals. A lamp (100 W) was employed as the irradiation source. Lamp temperature calibration was carried out with a tungsten filament optical pyrometer (Keller Pb06/01 AF3) up to $3300 \mathrm{~K}$. The set up shown in Figure 2 was used from several experimental arrangements mentioned in the literature due to its simplicity. ${ }^{30}$

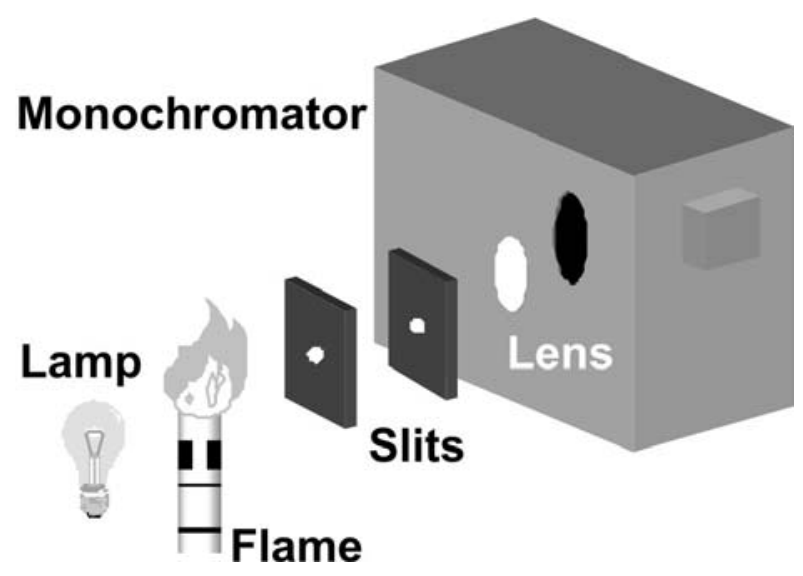

Figure 2. Experimental apparatus utilized in line reversal measurements.

\section{Results and Discussion}

No remarkable differences were observed in the emission spectra of the flames studied in this work. A spectrum of $\mathrm{CH}^{*}$ for a stoichiometric flame measured at $2.5 \mathrm{~mm}$ above the burner is shown in Figure 3.

The $\mathrm{CH}^{*}$ emission has an intensity maximum at $431.5 \mathrm{~nm}$. In this region, there is an overlapping of its 0-0 


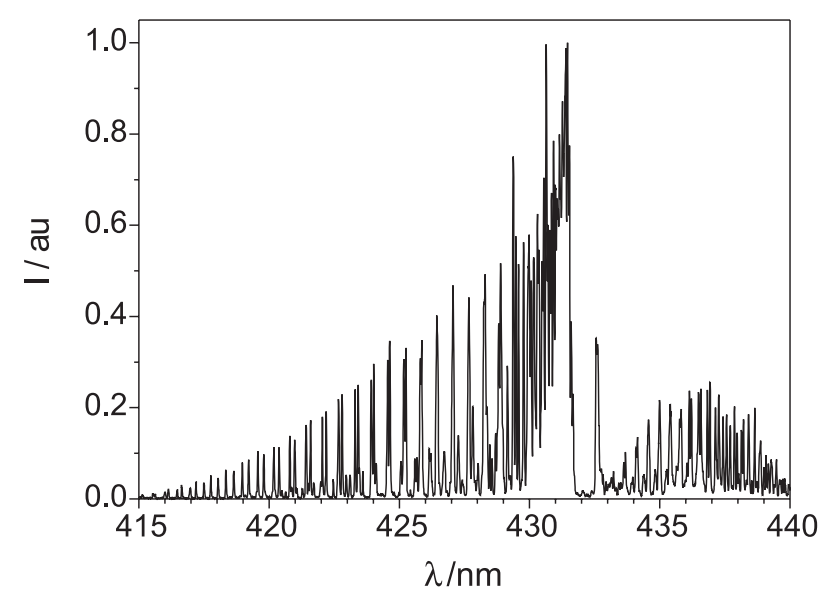

Figure 3. $\mathrm{CH}^{*}$ ro-vibrational spectra. Stoichiometric flame. Distance from burner of $2.5 \mathrm{~mm}$.

and 1-1 vibrational bands, as well as an isolated peak at $432.4 \mathrm{~nm}$ which corresponds to the 2-2 band. The spectral range between 416 and $425 \mathrm{~nm}$ is formed predominantly by the R-branch 0-0 band, with $J$ values from 11 to 20 . For $J \geq 7$ this branch shows a rotational structure well spaced with no interference from other peaks (Figure 4). ${ }^{35}$ This region, which appears as doublet peaks, was used for the rotational temperature determination.

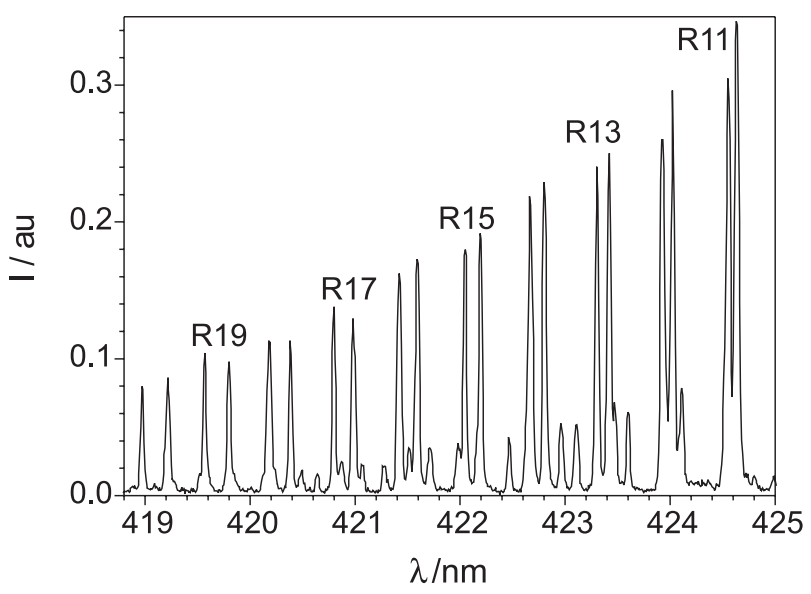

Figure 4. Experimental spectrum corresponding to R-branch $0-0 \mathrm{CH}^{*}$ vibrational band.

Rotational temperatures were determined from the slope of the straight lines obtained according to Equation 1. The longer wavelength peaks of the doublet were used in the experimental measurements of the peak intensities. $\mathrm{S}_{J^{\prime} J}$ and $\mathrm{E}_{J}$, were taken from the literature. ${ }^{15}$ Figure 5 corresponds to a typical Boltzmann's plot obtained from an average of three experimental spectra of a stoichiometric flame, at $2.5 \mathrm{~mm}$ above the burner. Each point in the graphic, therefore, corresponds to the average measured intensity, the straight line was calculated by linear regression and the rotational temperature determined from the slope of the line. Error temperature corresponds to the standard deviations of the temperature calculations.

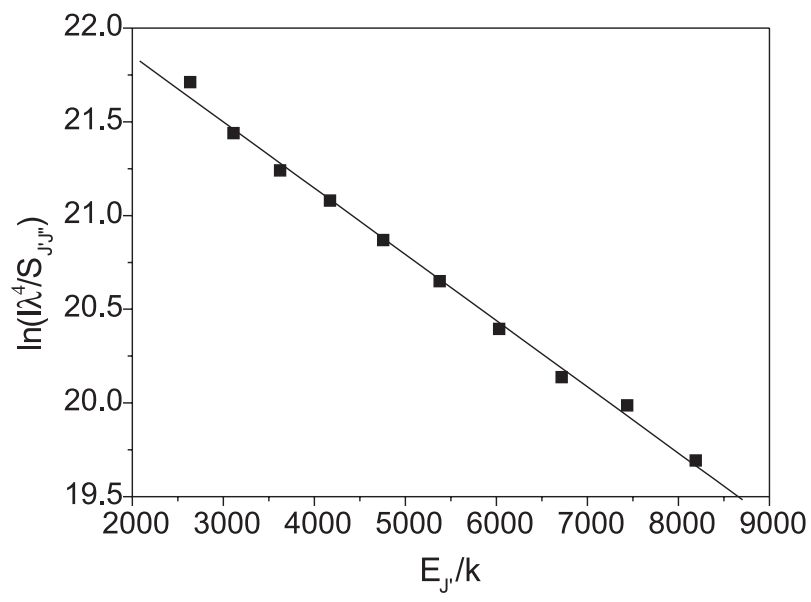

Figure 5. Average Boltzmann's plot for $\mathrm{CH}^{*}$ spectra. Stoichiometric flame. Distance from burner of $2.5 \mathrm{~mm}$. Calculated rotational temperature $=2830 \pm 47 \mathrm{~K}$.

Plot linearity indicates that radical $\mathrm{CH}^{*}$ population of the rotational energy states presents a Boltzmann's distribution. Similar plots were drawn for other experimental conditions and the results are summarized in Table 2 and Figure 6 . The shown errors correspond to the standard deviation of the whole spectral data at each distance above the burner.

Table 2. Experimental temperatures for $\mathrm{CH}^{*}$ radical as a function of equivalence ratio $(\phi)$ and burner distance $(\mathrm{mm})$

\begin{tabular}{lccc}
\hline Distance / mm & \multicolumn{3}{c}{ T / K } \\
\cline { 2 - 4 } & $\phi=1.43$ & $\phi=1.02$ & $\phi=0.78$ \\
\hline 5.5 & $2793 \pm 71$ & --- & --- \\
4.5 & $2965 \pm 66$ & --- & --- \\
3.5 & $2878 \pm 125$ & $2783 \pm 26$ & $2872 \pm 76$ \\
2.5 & $2784 \pm 60$ & $2859 \pm 47$ & $2817 \pm 58$ \\
1.5 & $2752 \pm 129$ & $2895 \pm 37$ & $2900 \pm 71$ \\
\hline
\end{tabular}

According to Figure 6, the emission signal could be observed only up to a distance of $3.5 \mathrm{~mm}$ for stoichiometric and $5.5 \mathrm{~mm}$ for rich flames. For higher distances, the intensity signal decreased sharply and could not be detected. Rotational temperature values did not show an appreciable variation with the equivalence ratio within the range of distances above the burner studied. The richflame temperature at $4.5 \mathrm{~mm}$ returned an over-adiabatic temperature value, probably due to an error in the flow meter set, i.e., the temperature determined corresponds to another flame composition. However, in general the 


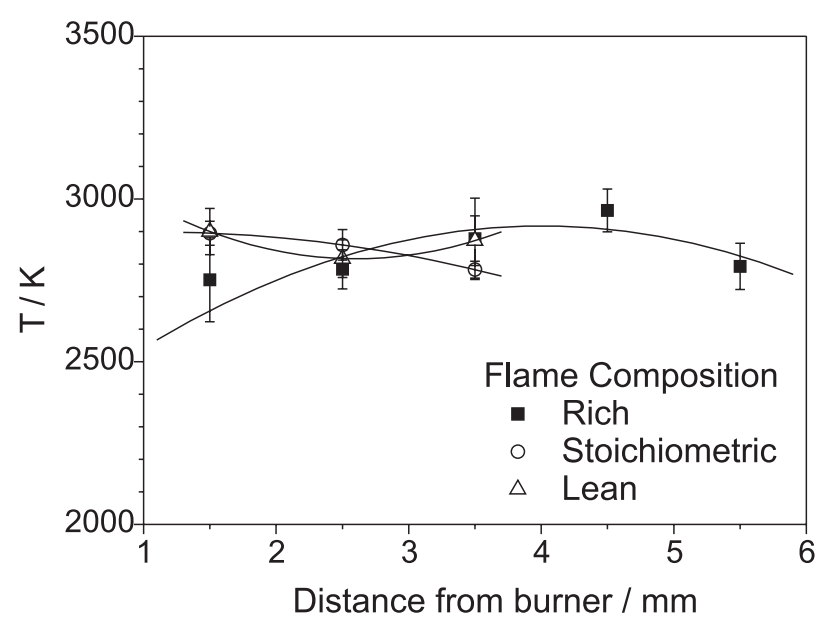

Figure 6. Experimental temperatures for $\mathrm{CH}^{*}$ radical as a function of equivalence ratio $(\phi)$ and distance above burner $(\mathrm{mm})$.

temperature distribution suggests an adiabatic behavior in the investigated flame region, corresponding to the inner cone of the flame, which is the mostly responsible for the chemiluminescent process in the flame. Indeed, rotational temperature values are very close to the flame adiabatic temperature: $2857 \mathrm{~K}, 2946 \mathrm{~K}$ and $2910 \mathrm{~K}$ for rich, stoichiometric and lean flames, respectively. If one assumed an adiabatic behavior of the analyzed region, the average value for $\mathrm{CH}^{*}$ rotational temperature of the butane flames investigated in this work is $2845 \pm 70 \mathrm{~K}$. Again, the measurement errors were calculated from the standard deviation of the whole set of temperature values.

In LIFBASE simulations, we chose the same spectral range as in the Boltzmann's plots (R-Branch region). An example of the comparison between experimental and simulated spectra is shown in Figure 7. The determined experimental spectral resolution was ca. $0.45 \mathrm{~nm}$.

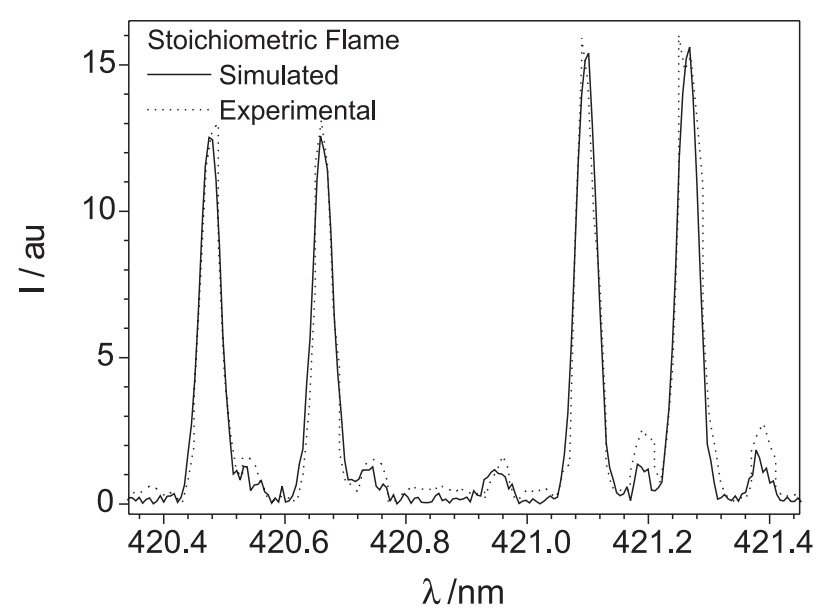

Figure 7. Comparison between simulated and experimental $\mathrm{CH}^{*}$ spectra. Stoichiometric flame. Zoom at R-Branch region. Distance of $2.5 \mathrm{~mm}$. $\mathrm{T}=2912 \mathrm{~K}$ for simulated spectrum.
There is a good agreement between both spectra shown in Figure 7. Besides R-branch region, rotational temperatures were also determined from the A-X transition band head (Figure 8). Spectra agreements are very good in the all wavelength region, with exception of the peak between $432 \mathrm{~nm}$ and $433 \mathrm{~nm}$. As mentioned before, this peak corresponds to the 2-2 vibrational band envelope.

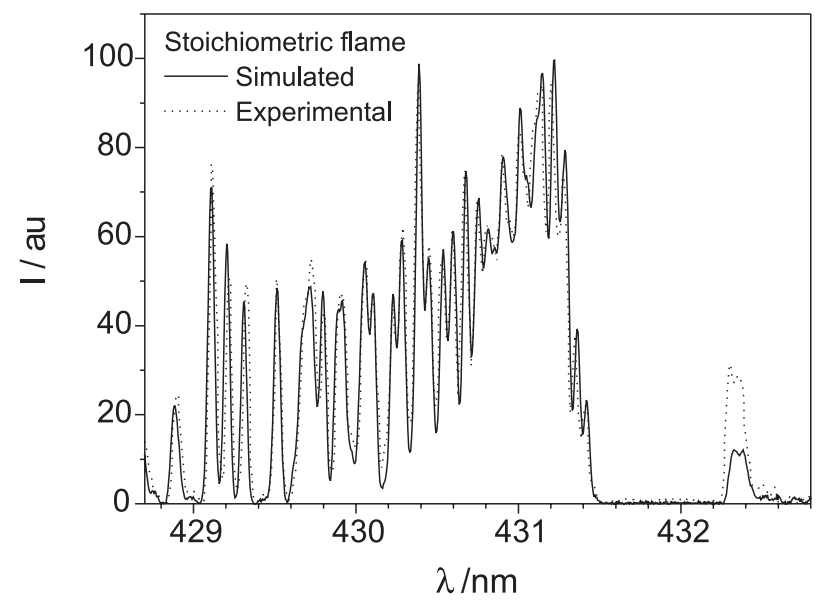

Figure 8. Comparison between simulated and experimental $\mathrm{CH}^{*}$ spectra. Stoichiometric flame. Band head region. Distance of $2.5 \mathrm{~mm}$. $\mathrm{T}=2912 \mathrm{~K}$.

A detailed spectra analysis shows that theoretical peak intensity is much lower than the experimental one. This indicates a larger number of excited species in vibrational level $v^{\prime}=2$ than expected in a thermal equilibrium system. This condition was observed in all the simulations. As discussed in Introduction, temperature concept only can be adopted in a system in thermodynamic equilibrium. In this case, temperature can describe several system properties, among them: all particle velocity distributions are in agreement with Maxwell's equation; excited state populations agree with Boltzmann's equation; and the electromagnetic radiation distribution corresponds to Planck's law. ${ }^{6,36}$ Other processes are related to detailed knowledge of all chemical reactions, ionizations and dissociations which occur in the system. In flames, these conditions are not quite achieved. In the inner cone reaction zone, for example, species do not have sufficient time for establishing equipartition of released chemical energy by chemiluminescent processes among the system freedom degrees. As the species leave the reaction zone, translational and rotational energies achieve equilibrium rapidly. However, vibrational and electronic levels relax more slowly. Former considerations permit a better understanding about 2-2 vibrational band. $\mathrm{CH}^{*}$ is not formed by thermal excitation, in most reaction mechanisms presented in literature. ${ }^{37}$ Thus, chemical 
species in rotational and vibrational excited energy levels would be subjected to collisional deactivation due to the chemical environment. From the obtained temperature, we can say that there is a Boltzmann equilibrium between rotational and translational energies for the investigated flame conditions. However, the intensity difference between the theoretical and experimental 2-2 band suggests that the vibrational modes still do not achieve the equilibrium with the rotational modes of 0-0 vibrational band. In fact, a study of low-pressure methane plasma showed that the 2-2 band lifetime is significantly lower than $0-0$ band: $32 \mathrm{~ns}$ and $45 \mathrm{~ns}$, respectively. ${ }^{38}$ To confirm this observation $\mathrm{CH}^{*}$ vibrational temperature was determined.

The major problem in $\mathrm{CH}^{*}$ vibrational temperature determination is the band overlapping that occurs in the studied spectral range. Nevertheless, this problem was resolved in the LIFBASE simulations, as the vibrational bands can be treated separately. The vibrational bands available in LIFBASE are: 0-0, 1-1, 2-2 and 3-3. The integrated area of the former vibrational bands was used for temperature determination by Boltzmann's method. Figure 9 shows an example of this determination. All the results obtained are listed in Table 3.

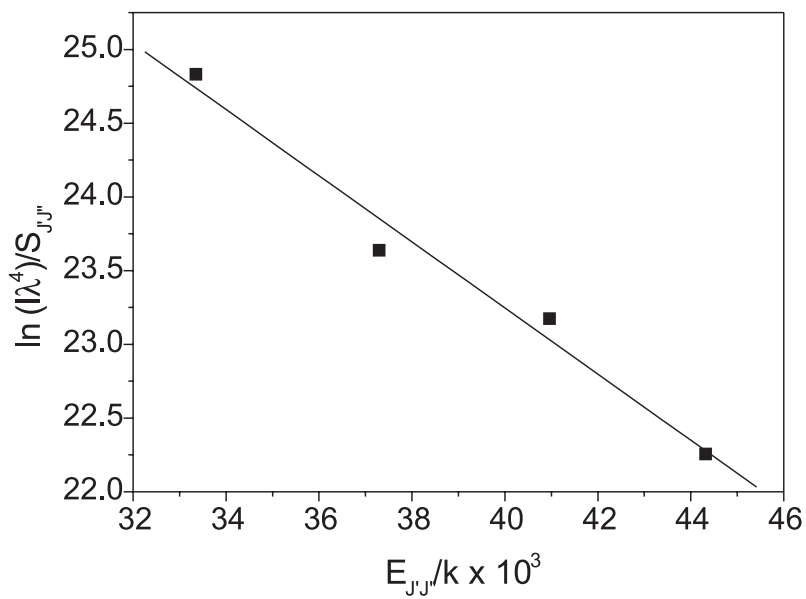

Figure 9. Vibrational Boltzmann plot. Distance of $2.5 \mathrm{~mm}$. Lean Flame. Vibrational temperature $=4459 \mathrm{~K}$.

Table 3. $\mathrm{CH}^{*}$ Vibrational temperature values

\begin{tabular}{lccc}
\hline Distance / mm & \multicolumn{3}{c}{$\mathrm{T} / \mathrm{K}$} \\
\cline { 2 - 4 } & $\phi=1.43$ & $\phi=1.02$ & $\phi=0.78$ \\
\hline 5.5 & $4300 \pm 109$ & --- & --- \\
4.5 & $4600 \pm 102$ & --- & --- \\
3.5 & $4650 \pm 202$ & $4400 \pm 41$ & $4400 \pm 116$ \\
2.5 & $4400 \pm 95$ & $4650 \pm 76$ & $4650 \pm 96$ \\
1.5 & $4600 \pm 216$ & $4550 \pm 58$ & $4600 \pm 113$ \\
\hline
\end{tabular}

According to Table 3, vibrational temperatures are significantly higher than rotational ones. As can be observed, there is no significant difference between the temperatures of each investigated flame neither in the distance above burner. This also contributed to the adiabatic behavior interpretation assigned to the flame region studied. Therefore, the calculated average vibrational temperature for the butane flames is $4600 \pm 127 \mathrm{~K}$. The measurement error is the standard deviation of all temperature listed in the Table 3. Although vibrational temperatures are higher, compared to the rotational ones, these results are in agreement with the concept of both temperatures. Studies have appointed which rotational and vibrational relaxation rates for diatomic hydrides are dependent on the chemical environment. Nevertheless, for $\mathrm{CH}^{*}$ radical the vibrational deactivation is very slow. ${ }^{39}$ Studies of the $\mathrm{CHBr}_{3}$ photolysis showed that vibrational energy transfer is more than an order of magnitude slower than rotational energy transfer. ${ }^{24}$ Thus, vibrational modes need thousands of collisions, while translational and rotational modes attain equilibrium with few collisions. ${ }^{6}$ Therefore, $\mathrm{CH}^{*}$ spontaneous emission, in the investigated flames, occurs before the equilibrium state between the rotational and vibrational modes are achieved.

The non-equilibrium of vibrational and rotational temperatures was reported in other works in literature. Emission spectroscopy of a methane-atmospheric air flame indicated rotational and vibrational temperatures of $1400 \mathrm{~K}$ and $4200 \mathrm{~K}$, respectively. ${ }^{3}$ These distinct values are attributed to the differences in energy transfer mechanisms for each degree of freedom. Characteristic times of rotational energy transfer and collision are ca. $10^{-14} \mathrm{~s}$ and $10^{-15} \mathrm{~s}$, respectively. Thus, colisional processes contributed to an effective way for rotational relaxation before the $\mathrm{CH}^{*}$ radical spontaneous emission, that $\mathrm{CH}^{*}$ radiative half-live time is ca. $0.56 \mu$ s. In this same work, $\mathrm{CH}^{*}$ ground state rotational temperature was determined by CARS, and a value of ca. $1500 \mathrm{~K}$ was obtained.

Studies of similar flames used in the present work also determined $\mathrm{OH}$ ground state rotational temperatures by $\mathrm{LIF}^{40}$ The average temperature was ca. $2600 \mathrm{~K}$, very close, hence, to $\mathrm{CH}^{*}$ rotational temperature found by emission spectroscopy.

Both results, demonstrated that radical at ground and excited states present similar temperatures. This indicates that, although chemiluminescence processes are originated from excited species, $\mathrm{CH}^{*}$ radiative half-live time is long enough to allow a minimum number of collisions to establish equilibrium of the rotational distribution in the excited state and also with the ground state, before spontaneous emission takes place. 
Emission spectroscopy results support the initial assumption that $\mathrm{CH}^{*}$ rotational temperatures can be considered as a flame temperature indicator. To confirm this hypothesis, flame temperature was determined by another diagnostic method: the sodium line reversal spectroscopy. This technique is totally independent of the $\mathrm{CH}^{*}$ natural emission and, as described in Introduction, is based only in sodium atomic spectrum. Under most burner conditions, sodium electronic temperature can be assigned as translational system temperature. ${ }^{30}$ An example of line reversal spectra can be seen in Figure 10. The signal reversal (emission to absorption) is observed at $10.5 \mathrm{~V}$ lamp voltages, corresponding to a calibrated temperature lamp of $2950 \mathrm{~K}$.

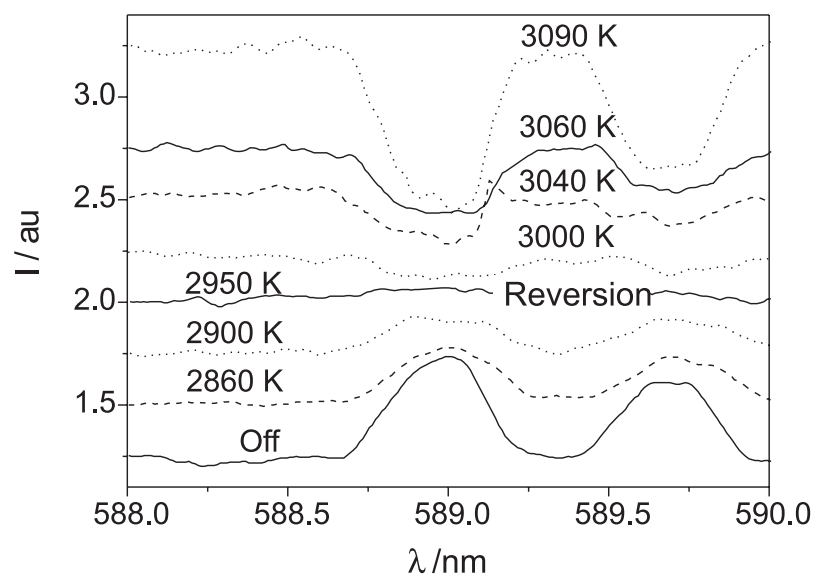

Figure 10. Sodium line reversal. Reversion can be observed at $10.5 \mathrm{~V}$. Stoichiometric flame. Distance of $4 \mathrm{~mm}$. T $=2950 \mathrm{~K}$.

Results in Figure 10 provide a good idea of the precision of the method. Assuming an error equivalent to half the minor range of the calibrated lamp temperatures, the maximum error is ca. $\pm 25 \mathrm{~K}$, hence, under $1 \%$ of the calculated flame temperature. To this error, however, it is necessary to add the measurement error from the optical pyrometer used in the lamp calibration. This value, based in statistical estimation, is ca. $\pm 2 \%$. Therefore, the maximum error is ca. $3 \%$. Line reversal temperature results are shown

Table 4. Temperatures obtained by Na line reversal method as function of equivalence ratio and distance above burner

\begin{tabular}{lccc}
\hline Distance / $\mathrm{mm}$ & \multicolumn{3}{c}{$\mathrm{T} / \mathrm{K}$} \\
\cline { 2 - 4 } & $\phi=1.43$ & $\phi=1.02$ & $\phi=0.78$ \\
\hline 4 & $2805 \pm 84$ & $2970 \pm 89$ & $2885 \pm 87$ \\
5 & $2845 \pm 85$ & $3040 \pm 91$ & $2945 \pm 88$ \\
6 & $2845 \pm 85$ & $2945 \pm 88$ & $2945 \pm 88$ \\
7 & $2845 \pm 85$ & $3005 \pm 90$ & $3005 \pm 90$ \\
8 & $2845 \pm 85$ & $3040 \pm 91$ & $3005 \pm 90$ \\
\hline
\end{tabular}

in Table 4. A comparison with $\mathrm{CH}^{*}$ rotational temperatures and flame adiabatic temperatures is shown in Figure 11.

Line reversal temperatures are in a good agreement with radical rotational temperatures. The major deviation is observed in stoichiometric flames, in the final inner cone
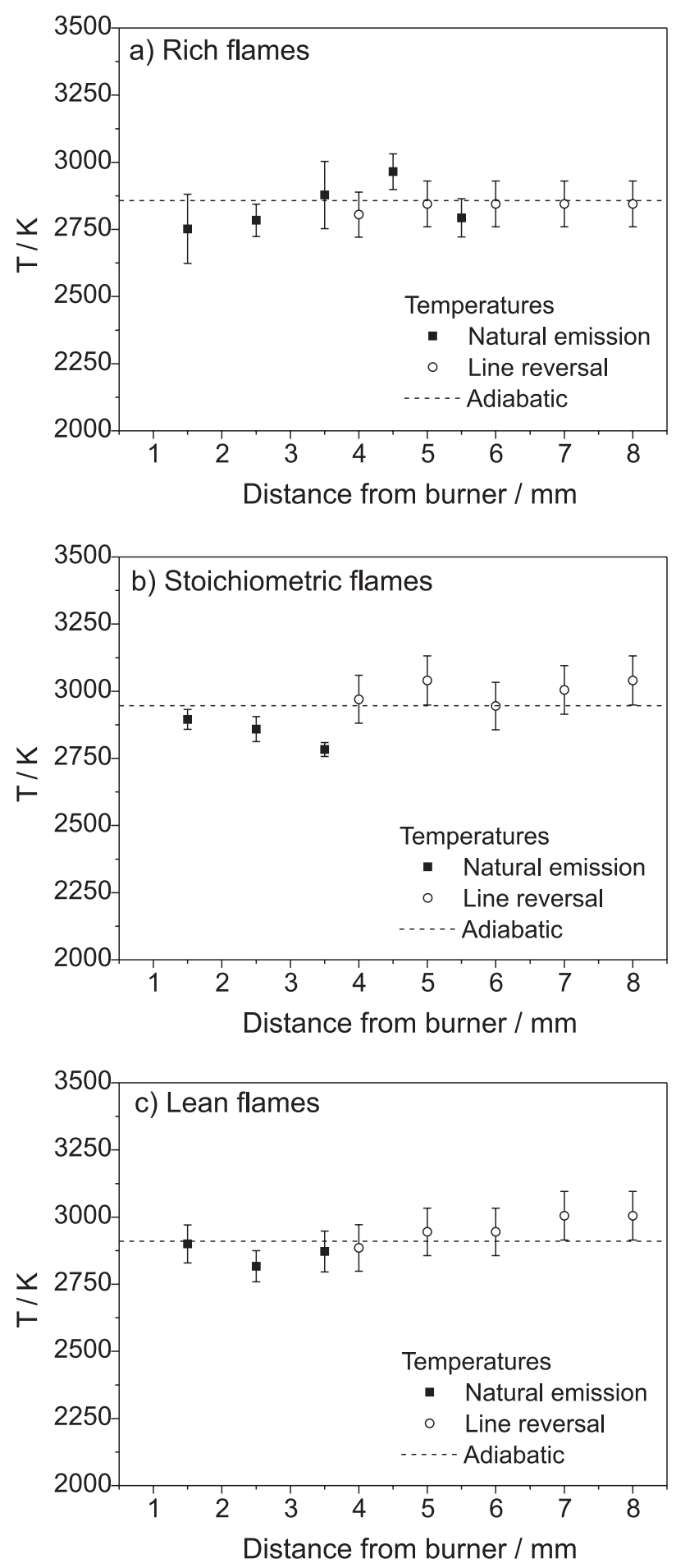

Figure 11. Comparison between line reversal results, $\mathrm{CH}^{*}$ rotational temperatures and flame adiabatic temperatures in (a) rich flames, (b) stoichiometrc flames and (c) lean fame. 
region, i.e., $3.5 \mathrm{~mm}$. As mentioned before, for this flame composition the intensity signal decreases sharply. Thus, the low rotational temperature can be assigned to poor intensity. However, the maximum deviation between line reversal and $\mathrm{CH}^{*}$ natural emission in this region is ca. $6 \%$. Average line reversal temperature was ca. $2930 \mathrm{~K}$.

As observed in natural emission, line reversal temperatures did not show remarkable variation as a function of distance from the burner, within the investigated flame region. With respect to the flame composition, rich flames showed temperatures slightly smaller than stoichiometric or lean flames. This result was expected, due to the lack of oxidant presented in the combustion mixture.

\section{Conclusions}

$\mathrm{CH}^{*}$ emission spectroscopy was shown to be an adequate technique for flame temperature determination. Rotational temperature values for this radical were ca. $2850 \mathrm{~K}$. Emission results were compared to the line reversal technique, which correspond to an average flame temperature of ca. $2930 \mathrm{~K}$. Therefore, the non-equilibrium condition reported in the past for rotational temperatures can be rejected in this work. However, this is not true for vibrational modes. Emission spectroscopy showed an average vibrational temperature of ca. $4600 \mathrm{~K}$. This overadiabatic value can be assigned to the lower ratio of energy transfer for vibrational modes than rotational ones.

\section{References}

1. Strahle, W.C.; An Introdution to Combustion, $1^{\text {st }}$ ed., Gordon and Breach: Amsterdam, 1993.

2. Gaydon, A. G.; Wolfhard, H. G.; Flames, $3^{\text {rd }}$ ed., Chapman and Hall: London, 1970; Broida, H. P.; J. Chem. Phys. 1951, 19 , 1383; Parker, J. G.; Phys. Fluids 1959, 2, 449; Kane, W. R.; Broida, H. P.; J. Chem. Phys. 1953, 21, 347; Cahen, C.; Sassi, M.; J. Quant. Spectrosc. Radiat. Transfer 1993, 49, 281.

3. Wange, J.; Wang, X.; Li, H.; Gu, X.; Spectrosc. Lett. 1990, 23, 515.

4. Hayashida, K.; Shirai, H.; Amagai, K.; Arai, M.; JSME Int. J. B-Fluid. T. 2002, 45, 201.

5. Coitout, H.; Faure, G.; Spectrosc. Lett. 1996, 29, 1201.

6. Broida, H. P.; Shuler, K. E.; J. Chem. Phys. 1957, 27, 933.

7. Lapworth, K. C.; J. Phys. E: Sci. Instrum. 1974, 7, 413.

8. Chigier, N. In Combustion Measurements; Chigier, N., ed.; Hemisphere Publishing Corporation: New York, 1991, ch. 1.

9. Kohse-Höinghaus, K.; Prog. Energy Combust. Sci. 1994, 20, 203.

10. Drakes, J. A.; Pritt, D. W.; Howard, R. P.; Hornkohl, J. O.; J. Quant. Spectrosc. Radiat. Transfer 1997, 57, 23
11. Gross, L. A.; Griffiths, P. R.; J. Quant. Spectrosc. Radiat. Transfer 1988, 39, 463.

12. Shvartsman, N. A.; Russ. J. Phys. Chem. 1975, 49, 1321; Karpetis, A. N.; Gomez, A.; Combust. Flame 2000, 121, 1; Luque, J.; Crosley, R. R.; Appl. Phys. B 1996, 63, 91; Sandrowitz, A. K.; Cooke, J. M.; Glumac, N. C.; Appl. Spectrosc. 1998, 52, 658; Blevins, L. G.; Renfro, M. W.; Lyle, K. H.; Laurendeau, N. M.; Gore, J. P.; Combust. Flame 1999, 118, 684; Luque, J.; Crosley, R. R.; Appl. Phys. B 1996, 63, 91; Klein-Douwel, R. J. H.; Jeffries, J. B.; Luque, J.; Smith, G. P.; Crosley, D. R.; Combust. Sci. Technol. 2001, 167, 291; Laurendeau, N. M.; Prog. Energy Combust. Sci. 1988, 14, 147; Lederman, S.; Prog. Energy Combust. Sci. 1977, 3, 1; Egermann, J.; Seeger, T; Leipertz, A.; Appl. Opt. 2004, 43, 5564; Daily. J. W.; Prog. Energy Combust. Sci. 1997, 23, 133; Seeger, T; Leipertz, A.; Appl. Opt. 1996, 35, 2665.

13. Zimmer, L.; Tachibana, S.; Tanahashi, M.; Shimura, M.; Miyauchi, T.; Proc. 6th Symposium on Smart Control of Turbulence, www.turbulence-control.gr.jp, accessed in August, 2007.

14. Joklik, R. G.; Daily, J. W.; Pitz, W. J.; Proc. Comb. Inst. 1986, 21, 895; Higgins, B.; McQuay, M.Q.; Lacas, F.; Candel, S.; Fuel 2001, 80, 1583.

15. Kim, J. S.; Cappelli, M. A.; J. Appl. Phys. 1998, 84, 4595.

16. Higgins, B.; McQuay, M.Q.; Lacas, F.; Candel, S.; Fuel 2001, 80, 1583.

17. Bertran, C. A.; Marques, C. S. T.; Benvenutti, L. H.; Combust. Sci. Technol. 1998, 139, 1.

18. Durie, R. A.; Proc. Phys. Soc. A 1952, 65, 125.

19. Broida, H. P.; J. Chem. Phys. 1953, 21, 340.

20. Broida, H. P.; J. Chem. Phys. 1951, 19, 1383.

21. Fissan, H. J.; Combust. Flame 1972, 19, 11.

22. Durie, R. A.; Proc. Phys. Soc. 1952, A 65, 125; Broida, H. P.; J. Chem. Phys. 1953, 21, 340.

23. Gaydon, A. G.; The Spectroscopy of Flames, $1^{\text {st }}$ ed., Chapman and Hall: London, 1957; Pearse, R.W.B; Gaydon, A. G.; The Identification of Molecular Spectra, $4^{\text {th }}$ ed., Chapman and Hall: London, 1976.

24. Cooper, J. L.; Whitehead, J. C.; J. Chem. Soc., Faraday Trans. 1993, 89, 1287

25. Brennen, W.; Carrington T.; J. Chem. Phys. 1967, 46, 7; Math, N. N.; Savadatti, M. I.; J. Quant. Spectrosc. Radiat. Transfer 1985, 34,75

26. Crichton, H. L.; Murray, C.; McKendrik K. G.; Phys Chem. Chem. Phys. 2002, 4, 5768

27. Pellerin, S.; Koulidiati, J.; Motret, O.; Musiol, K.; Graaf, M. de; Pokrzywka, B.; Chapelle, J.; High Temp. Mater. Processes 1997, 1, 493.

28. Herzberg, F. R. S. G.; Molecular Spectra and Molecular Strucuture, $2^{\text {nd }}$ ed., Van Nostrand Reinhold Company: London, 1950. 
29. Mak, W. H.; UTIA Techanical Note 1963, 66, 1; Thomas, D. L.; Combust. Flame 1968, 12, 541.

30. Loomis, A. G.; Perrot, G. St. J.; Ind. Eng. Chem. 1928, 20, 1004; Yang, D.; Xu, H.; Wang, J.; Zhao, B.; Spectrosc. Lett. 2001, 34, 109.

31. Lacava, P. T.; PhD Thesis, Instituto Nacional de Pesquisas Espaciais, INPE, São José dos Campos, Brazil, 1995.

32. Luque, J.; Crosley, D. R.; LIFBASE; Database and spectral simulation (version 1.5); SRI International Report MP 99-009, USA, 1999.

33. Morley, C.; GASEQ; Chemical Equilibria in Perfect Gases (version 0.76); www.gaseq.co.uk, accessed in August 2007.

34. Pellerin, S.; Musiol, K.; Motret, O.; Pokrzywka, B.; Chapelle, J.; J. Phys. D: Appl. Phys. 1996, 29, 2850.

35. Couris, S.; Anastasopoulou, N.; Fotakis, C.; Chem. Phys. Lett. 1994, 223, 516.
36. Reif, I.; Fassel, V. A.; Kniseley, R. N.; Spectrochim. Acta 1973, $28 B, 105$.

37. Smith, G. P.; Luque, J.; Park, C.; Jeffries, J. B.; Crosley, D. R.; Combust. Flame 2002, 131, 59.

38. Luque, J.; Juchmann; Jeffries, J. B.; Appl. Opt. 1997, 15, 3261 .

39. Garland, N. L.; Crosley, D. R.; Appl. Opt. 1985, 24, 4229.

40. Dos Santos, L. R.; PhD Thesis, Universidade de São Paulo, Brazil, 2005.

Received: August 27, 2007

Web Release Date: August 11, 2008

FAPESP helped in meeting the publication costs of this article. 